\title{
Studies on Human Mandibles
}

\author{
T.Jayachandra Pillai ${ }^{1}$, T.Sobha Devi ${ }^{2}$, C.K.lakshmi Devi ${ }^{3}$ \\ ${ }^{I}$ Proffessor, Dept of Anatomy, S.V. Medical College, Tirupati NTRUHS India. \\ ${ }^{2}$ Assistant proffessor, Dept of Anatomy, S.V. Medical College, Tirupati NTRUHS India. \\ ${ }^{3}$ Associate proffessor, Dept of Anatomy, S.V. Medical College, Tirupati NTRUHS India.
}

\begin{abstract}
Identification of human skeletal remains is a critical problem and is very important in medicolegal and anthropological work. The determination of sex of an individual is important and necessary both in the living and the dead for medico legal purpose. It is particularly essential when only skeletal remains are available. In the living and the dead, in fresh conditions. Difficulty arises when sex is to be decided based on a few skeletal remains. Good number of human mandibles was collected from the burial grounds in and around Tirupati. They were sorted out and intact adult normal mandibles were selected for the present work. For each mandible accurate measurements were taken for 22 variables namely, (1) Symphyseal height, (2) Coronoid height, (3) Minimum breadth of ramus, (4) Maximum breadth of ramus, (5) Height of ramus - right, (6) Height of ramus - left, (7) Body height, (8) Body thickness, (9) Body length,(10) Bigonial dimeter, (11) Bicondylar diameter, (12) Bimental breadth, (13) Mandibular angle, (14) Length of lowe jaw, (15) Interincisor width, (16) Interprmolar width, (17) Intermolar width, (18) Arch length, (19) Anthropometric arch length, (20) Anthropometric arch width, (21) Bicornoid width and (22) Mandibular index.The measurements were compared to the values of known sex to distinguish the sex of mandible.
\end{abstract}

Keywords: Mandible, Symphyseal height, coronoid height, Bigonial diameter, Bicondylar diameter, Mandibular angle

\section{Introduction}

The mandible is a latin word which means lower jaw. Mandere means to chew. Thus the word mandible is derived.The mandible is the largest, strongest and lowest bone in the face. This is only bone in the skull (with the exception of tympanic ossicles) that is capable of separate movement. Mandible is formed to carry the lower teeth opposing those of upper jaw, gives insertion to the muscles of mastication and origin to muscles of tongue, floor of the mouth and some muscles of facial expression.Identification of human skeletal remains is a critical problem and is very important in medicolegal and anthropological work. The determination of sex of an individual is important and necessary both in the living and the dead for medico legal purpose. It is particularly essential when only skeletal remains are available. In the living and the dead, in fresh conditions. difficulty arises when sex is to be decided based on a few skeletal remains. The reconstruction of man's part after death would be impossible without bones. Bones often survive the process of decay and therefore provide the major evidence of human age and sex after death. The teeth and craniofacial skeleton are best preserved parts of human remains. The mandible is the strongest bone of facial skeleton and the best preserved after death. In mass disaster like air crashes, wars, railway accidents, floods etc., it is the medicolegal job to work with unknown variable to describe the skeletal remains and provide identification. By sex determination, the job of identification would be reduced to half.Sex can be more accurately determined after attainment of puberly. The sex differences are well marked in the bony pelvis and skull. An accurate determination of sex can be done in over 90 percent of cases using only pelvis and skull (Krogman, 1962, Modi, 1977,Ref.19,24). Sex determination from a given bone of an individual is of great value for medical jurist who often gives expert opinion from the available skeletal remains. Skull is the most easily sexed portion of skeleton next to pelvis. As a component of the skull, mandible shares the character. The study of identification of sex for a single bone is not only important medicolegally but anthropologically. If the mandible alone is available besides sex, age and race also can be determined. Mandible, maxilla and teeth are best preserved parts of the body after death. The mandible has been extensively studied (Martin 1936, Morant 1936, Clever 1937, Hrdlicka 1940, Stewart 1954, Hanihara 1959, Giles 1964,Ref.23,25,7.15,32,13,12). Their work was based on biometric study, mathematical methods, parameters like symphyseal height, gonial angle, bigonial breadth and discriminant function analysis etc. In India, Heereshchandra and Malaviya (1972Ref.14,15) studied subjective signs of mandible taking into account that chin is squarer in male and round in female. They also studied angle of mandible. Diwan (1987Ref.9), Fakruddin (1987Ref.9) and Shroff (1987,Ref.9) studied using discriminant function scores (Rajagopal Reddy, 1978,Ref.28). 


\section{Materials And Methods}

The material used for the study contained 88 human mandibles of unknown sex obtained from different grave yards in Tirupati town and from the Departmental pool. The bones collected are free from any pathological lesions or fractures. Totally edentulous mandibles with absorbed alveolar margins were excluded from this study. The bones collected roughly belong to the age group of 18 to 60 years.

The following parameters were taken with Metal sliding calliper, Mandibulometer(fig.1) measured on mandible in order to determine the sex. 1.Symphyseal height, 2.Coronoid height,3.Minimum breadth of ramus, 4.Maximumbreadth of ramus, 5. Height of ramus - right, 6.Height of ramus - left,7.Body height,8.Body thickness,9.Body length,10.Bigonial diameter,11.Bicondylar diameter,12.Bimental breadth, 13.]Mandibular angle,14.Length of lower jaw,15.Interincisor width,16.Interpremolar width,17.Intermolar width,18.Arch length,19.Anthropometric arch length,20.Anthropometric arch width,21.Bicoronoid width22.Mandibular indexThe data collected is statistically analyzed, subjected to Factor analysis and tabulated.

The data collected on the 22 characteristics is possibly intercorrelated. There could be significant interrelationships among these variables. In order to identify certain latent factors that could explain the variation in these characteristics, Factor analysis has been applied. This method is based on another statistical principle called principal components. The objective of Factor analysis is to identify as many factors as possible in such a way that they are uncorrelated (a sort of independence). The calculations are quite involved and the procedure also requires an in depth knowledge of statistical tools. This procedure is however available in a number of software packages and SPSS (Statistical Packages for Social Sciences) is one such software. This tool has been applied to the present data with the objective of identifying the principal components. The data on 88 cases has been analyzed in SPSS with the following options.Extraction of factors by principal components. Factors whose Eigenvalue is $<1.0$ are not considered (table -5)Correlation matrix among the variables (table 4)Rotation of factors by Varimax method. This portion of analysis ensures that the extracted factors are almost independent.Rearrangement of factors by the size of their loadings.

Figure. 1

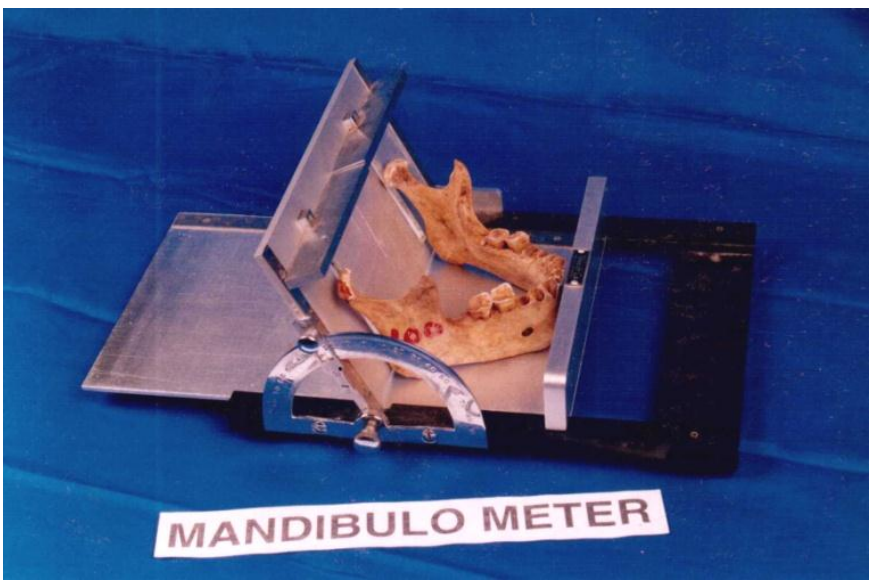

\section{Discussion}

Dry human mandibles of unknown sex were collected in large number from different grave yards in the around Tirupati and from the departmental pool. By eliminating pathologically misfit mandibles, 88 numbers fit for the present work were selected. Each mandible was carefully measured for 22 parameters already described in Materials and Methods. The data thus obtained is tabulated (table - 1). An attempt is made to identify the mandibles of either sex by measuring various parameters and by comparing the data with the data of known sex.

The symphyseal height varies from $23 \mathrm{~mm}$ to $40 \mathrm{~mm}$ with a mean value of $29.6 \mathrm{~mm}$ (table -2 ). When this compared to the range of the known sex, 44 mandibles out of 88 could be identified as belonging to male and 37 to female while 7 remain undecided (table -3 ). However, when other parameters are taken into consideration the significance of symphyseal height deciding the sex decrease. Higher mandibular symphyseal height in male has been reported earlier (Mallik, 1969, Surendranath, 1989REF.22,33). This is in correlation with the present observation.

When coronoid height of all the mandibles under investigation is measured it ranges from $48 \mathrm{~mm}$ to 71 $\mathrm{mm}$ with a mean value of $59 \mathrm{~mm}$. with the help of this parameter out of 88 mandibles 52 could be designated as belonging to male and 36 to female. In males there is well developed coronoid process (Brothwell, 1981,Ref.2). Minimum breadth of the ramus ranges from $23 \mathrm{~mm}$ to $36 \mathrm{~mm}$ with a mean value of $30.5 \mathrm{~mm}$. With the help of this parameter, out of 88 mandibles 55 could be said to be male, 28 to be female and 5 remain undecided. Maximum breadth of ramus ranges from $28 \mathrm{~mm}$ to $47 \mathrm{~mm}$ with a mean value of $39 \mathrm{~mm}$ by which 44 could be 
regarded as male, 40 as female and 4 undecided. It is stated earlier that in white races the mandible shows higher and narrower ramus while in the black races the ramus is lower, wider and more vertical (Shultz, 1933Ref.31). There was greater breadth of the ascending ramus compared to 15 female mandibles (Mallik, 1969). Male mandibles will have broader and longer ascending ramus (Brothwell 1981, Surendranath 1989,Ref.2,33). The ramus was more vertical in males than females (Prakash and Abdi, 1987,Ref.27). In this connection it is interesting to note that the mandibles that are regarded as belonging to male in the present study show that the maximum and minimum breadth of ramus are in correlation with the earlier findings. The height of the ramus is measured on right and left sides for all the mandibles. Right side mean value shows slight higher value by $3 \mathrm{~mm}$ than left side. This difference may be due to the difference in the chewing habit of the individual. This needs further investigation since there were no such observations in the past.

Body height of the mandible ranges from $18 \mathrm{~mm}$ to $33 \mathrm{~mm}$ with a mean value of $26.5 \mathrm{~mm}$. By this parameter alone 71 can be said to be male, 14 to be female and 3 remain undecided. Body thickness ranges from $11 \mathrm{~mm}$ to $18 \mathrm{~mm}$ with mean value of $14.6 \mathrm{~mm}$ by which 81 belong to male, 6 female and 1 undecided. Body length ranges from $60 \mathrm{~mm}$ to $85 \mathrm{~mm}$ with a mean value of $75 \mathrm{~mm}$ by which 21 belong to male, 61 to female and 6 undecided. The body height, length and thickness though facilitating to sex the mandibles at higher percentage, this is regard as an insignificant factor in the known sex (seshaiah, 1992,Ref.30).

Bigonial diameter ranges from $80 \mathrm{~mm} 112 \mathrm{~mm}$ with a mean value of $92 \mathrm{~mm}$ by which 55 mandibles are said to be male and 33 to be female. The bigonial diameter is influenced by the eversion or inversion of gonial angle. Eversion of gonial angle is characteristic of male and inversion is that of female (lockhart, 1965,Ref.21). In the present study,55 mandibles have shown higher biogonial diameter and hence they are regarded as belonging to male and the rest female.

Bicondylar diameter ranges from $91 \mathrm{~mm}$ to $126 \mathrm{~mm}$ with a mean value of $110 \mathrm{~mm}$ by which 46 mandibles can be said to be male,37to be female and 5 undecided. It is stated that sharp tubercles on the medial and lateral aspects of anterior surfaces of mandibular condyles are stress indicators (krogman,1962,Ref.19). Mandibular condyles were smaller in females (Tedeshi,1977,Ref,34). In the present study those mandibles that are designated as belonging to females showed smaller condyles resulting in lesser diameters. This is in accordance with the findings of Tedeshi, 1977. However the difference in the bicondylar diameter of male and female mandibles were reported to be insignificant. Bimental breadth from $37 \mathrm{~mm}$ to $50 \mathrm{~mm}$ with a mean value of $43 \mathrm{~mm}$ by which 52 mandibles can be said to be male and 36 to be female. This parameter was reported to be significant.

Mandibular angle ranges from $104^{0}$ to $137^{\circ}$ with a mean value $123^{\circ}$ by which 62 mandibles have greater and everted gonial angle (Shultz, 1933,Ref.31). Eversion of angle is characteristic of male and inversion in that of female (Lockhart, 1965,Ref.21). It was concluded that round chin mandible with inversion or eversion can not be a female one oand 59.26 percent of accuracy in sex determination is possible with mandible (Heereshchandra and Malaviya, 1972,Ref.14,15). Male mandibles will have well developed and flaring gonial regions (Brothwell, 1981,Ref.2). Mean value of mandibular angle was more in females- $118.6^{\circ}$, females $123.0^{\circ}$ (prakash and Abdi, 1987,Ref.27) In males the lateral aspsect of the angle of the mandible shows rough or rigid appearance. In females the angle of the jaw is often more rounded and gracile in construction. The attachment surface of the masseter muscle is often much smoother (Whittaker, D.K.and Mcdonald,1989,Ref.36). In the present study. Those that are considered as females presented with higher mandibular angle and males with lower mandibular angle. These findings are in agreement with the findings of Prakash and Abdi,1987,Ref.27).

Inter incisor width ranges from $13 \mathrm{~mm}$ to $20 \mathrm{~mm}$ with mean value of $16 \mathrm{~mm}$ by which 48 mandibles belong to male and 40 to female. Inter premolar width ranges from $28 \mathrm{~mm}$ to $40 \mathrm{~mm}$ with mean value of $34 \mathrm{~mm}$ by which 65 mandibles can be said to be male and 23 to be female. Intermolar width ranges from $39 \mathrm{~mm}$ to $53 \mathrm{~mm}$ with a mean value of $44 \mathrm{~mm}$ by which 67 mandibles can be said to be male and 21 to be female. Though the mandibles are sexed based on the above parameters they were considered as insignificant in the earlier studies. However, these parameters are taken into account for the purpose of factor analysis.

Arch length ranges from $34 \mathrm{~mm}$ to $50 \mathrm{~mm}$ with mean value of $42 \mathrm{~mm}$ by which 86 mandibles shows male measurements and 2 females. In the known sex the difference between the male and female is insignificant and hence in the present study almost all are falling into one category. It has been stated that the dental arch forms appear to be strongly influenced by genetic factors, although environmental factors are more important (Christopher-L.B.Lavelle,1977,Ref.5). Anthropometric arch length ranges from $48 \mathrm{~mm}$ to $64 \mathrm{~mm}$ with a mean value of $42 \mathrm{~mm}$ by which 31 mandibles can be grouped as males and 57 as females. In the known sex the difference between the male and female of anthropometric arch width is said to be a significant parameter.

Bicoronoid width ranges from $70 \mathrm{~mm}$ to $107 \mathrm{~mm}$ with a mean value of $92 \mathrm{~mm}$ by which 49 mandibles can be grouped as males and 39 as females. Though the difference between male and female is considered as insignificant in the earlier studies, a clear difference is observed in the present study. 
The values of the two parameters, namely length of lower jaw and mandibular index in the present study totally differ from the values of the mandibles of known sex. Therefore, these two parameters were not applied to identify the sex of the mandible with reference to known sex and they are taken into consideration for factor analysis.

The foregoing account reveals that every parameter independent of other parameters contributes certain percent of certainty to decide the sex of mandible of unknown sex. This percentage of certainty tilts when considered in the light of the percentage of other parameters. Therefore, it is clear that based on no single parameter, sex of the mandible can not be decided. All the parameters have to be considered together and for this purpose Factor analysis is resorted to. Thus 6 factors have been extracted and they could explain 75.2 percent of total variation in the data from all variables. The factors are shown in the table-5. Subject to the limitations of the sample data, 6 dominating characteristics that could possibly explain the nature of mandibles are Height of the ramus - right,Body thickness,Anthropometric arch width,Inter incisor width,Mandibular index,Mandibular angleThese six variables are identified by selecting the first variable in each factor. In the present study the 88 mandibles of unknown sex by carefully studying all the 22 parameters with reference to known values of either sex and by subjecting the data to Factor analysis it is known that with 75 percent certainty one can sex the mandible.

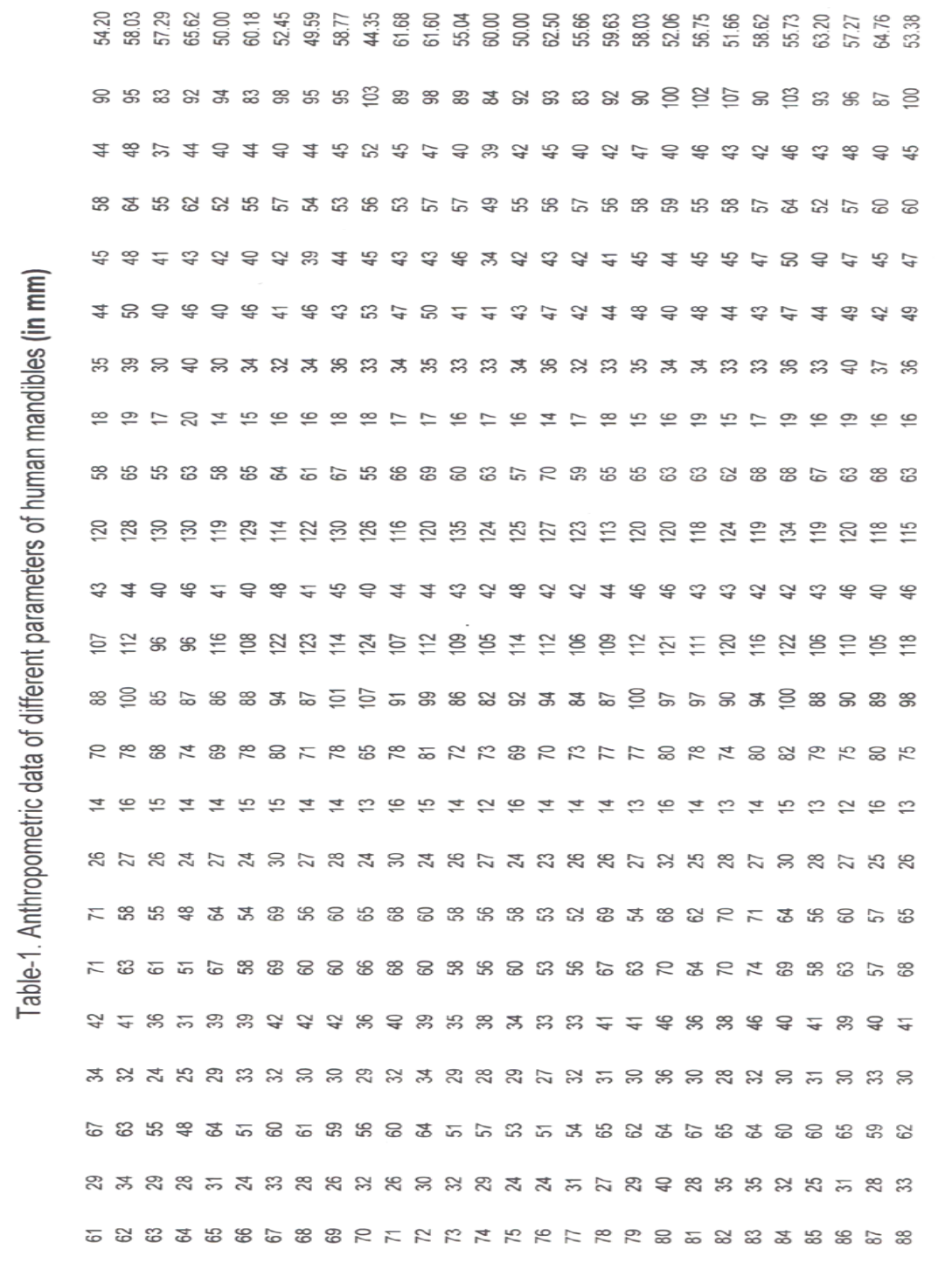


Table-2. Descriptive Statistics

\begin{tabular}{|c|l|c|c|c|c|}
\hline \multirow{2}{*}{ S.No. } & \multirow{2}{*}{ Name of the variable } & \multicolumn{2}{|c|}{ Range } & \multirow{2}{*}{ Mean } & Standard \\
\cline { 3 - 4 } & & Minimum & Maximum & & 29.63 \\
\hline 1 & Symphyseal height & 23.00 & 40.00 & 3.51 \\
\hline 2 & Coronoid height & 48.00 & 71.00 & 59.37 & 5.03 \\
\hline 3 & Minimum breadth of ramus & 23.00 & 36.00 & 30.50 & 2.73 \\
\hline 4 & Maximum breadth of ramus & 28.00 & 47.00 & 39.21 & 3.42 \\
\hline 5 & Height of ramus - right & 51.00 & 76.00 & 62.92 & 5.30 \\
\hline 6 & Height of ramus - left & 48.00 & 76.00 & 61.05 & 5.72 \\
\hline 7 & Body height & 18.00 & 33.00 & 26.55 & 2.68 \\
\hline 8 & Body thickness & 11.00 & 18.00 & 14.60 & 1.35 \\
\hline 9 & Body length & 60.00 & 85.00 & 75.31 & 4.83 \\
\hline 10 & Bigonial diameter & 80.00 & 112.00 & 92.22 & 6.37 \\
\hline 11 & Bicondylar diameter & 91.00 & 126.00 & 110.32 & 6.52 \\
\hline 12 & Bimental breadth & 37.00 & 50.00 & 43.19 & 2.76 \\
\hline 13 & Mandibular angle & $104.00^{*}$ & $137.00^{*}$ & $122.55^{*}$ & $67.83^{*}$ \\
\hline 14 & Length of lower jaw & 50.00 & 74.00 & 63.98 & 4.78 \\
\hline 15 & Inter incisor width & 13.00 & 20.00 & 15.89 & 1.68 \\
\hline 16 & Inter premolar width & 28.00 & 40.00 & 33.75 & 2.36 \\
\hline 17 & Inter molar width & 39.00 & 53.00 & 44.35 & 2.76 \\
\hline 18 & Arch length & 34.00 & 50.00 & 42.40 & 2.82 \\
\hline 19 & Anthropometric arch length & 48.00 & 64.00 & 56.21 & 2.94 \\
\hline 20 & Anthropometric arch width & 34.00 & 52.00 & 42.39 & 2.99 \\
\hline 21 & Bicoronoid width & 70.00 & 107.00 & 91.97 & 5.69 \\
\hline 22 & Mandibular index & 44.35 & 67.59 & 58.13 & 4.75 \\
\hline & & & & & \\
\hline
\end{tabular}

$N=88$;

Measurements in $\mathrm{mm}$

* measured in degrees

Table-3. Sexing of the mandible by individual parameters

\begin{tabular}{|c|c|c|c|c|c|}
\hline S.No. & Name of the parameter & Male & Female & Undecided & Tota \\
\hline 1 & Symphyseal height & 44 & 37 & 7 & 88 \\
\hline 2 & Coronoid height & 52 & 36 &. & 88 \\
\hline 3 & Minimum breadth of ramus & 55 & 28 & 5 & 88 \\
\hline 4 & Maximum breadth of ramus & 44 & 40 & 4 & 88 \\
\hline 5 & Height of ramus - right & 82 & 6 & .. & 88 \\
\hline 6 & Height of ramus - left & 77 & 11 &. & 88 \\
\hline 7 & Body height & 71 & 14 & 3 & 88 \\
\hline 8 & Body thickness & 81 & 6 & 1 & 88 \\
\hline 9 & Body length & 21 & 61 & 6 & 88 \\
\hline 10 & Bigonial diameter & 55 & 33 & .. & 88 \\
\hline 11 & Bicondylar diameter & 46 & 37 & 5 & 88 \\
\hline 12 & Bimental breadth & 52 & 36 &. & 88 \\
\hline 13 & Mandibular angle & 62 & 26 & .. & 88 \\
\hline 14 & Inter incisor width & 48 & 40 &.$\cdot$ & 88 \\
\hline 15 & Inter premolar width & 65 & 23 & 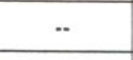 & 88 \\
\hline 16 & Intermolar width & 67 & 21 &.. & 88 \\
\hline 17 & Archlength & 86 & 2 & .. & 88 \\
\hline 18 & Anthropometric arch length & 42 & 47 &.- & 88 \\
\hline 19 & Anthropometric arch width & 31 & 57 & .. & 88 \\
\hline 20 & Bicoronoid width & 49 & 39 &.. & 88 \\
\hline
\end{tabular}




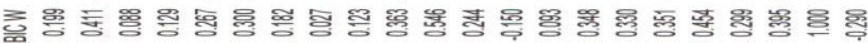

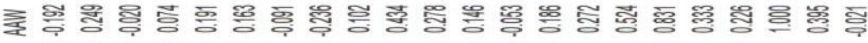

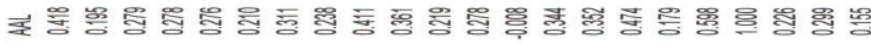

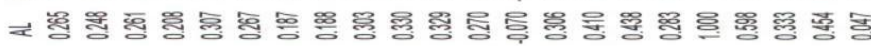

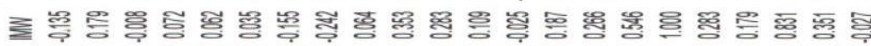

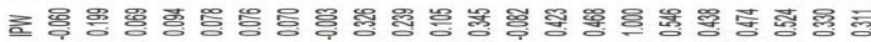

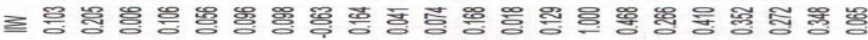

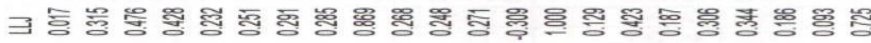

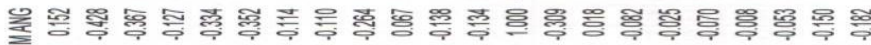

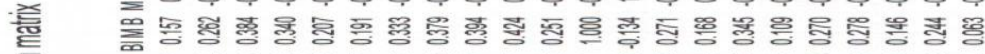

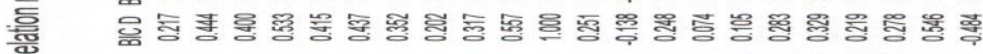

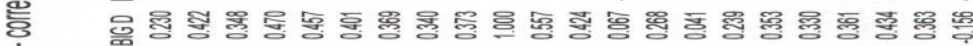

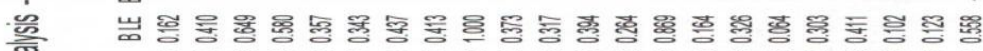

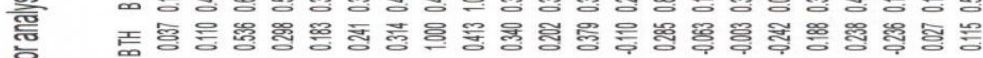

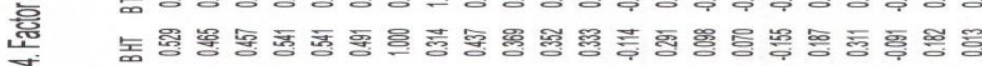

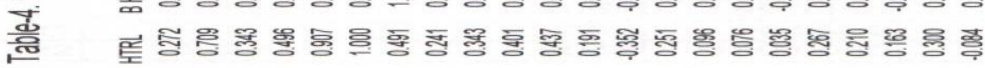

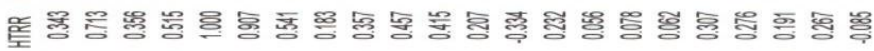

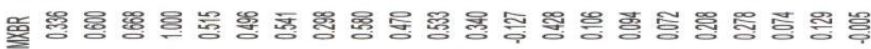

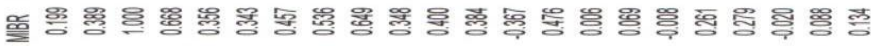

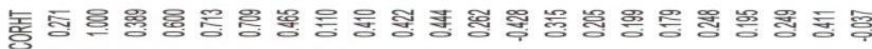

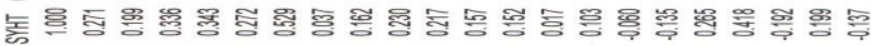

Table-5. Factor Analysis - Extraction of Factors

\begin{tabular}{|c|c|c|c|c|c|c|}
\hline \multicolumn{3}{|c|}{ Total Variance Explained } & & & & \\
\hline & Initial Eigen & ivalues & & \multicolumn{3}{|c|}{ Extraction Sums of Squared Loadings } \\
\hline Component & Total & $\%$ of Variance & Cumulative & fotal & $\%$ of Variance & Cumulative \% \\
\hline 1 & 6.7681 & 30.7641 & 30.7641 & 6.7681 & 30.7641 & 30.7641 \\
\hline 2 & 3.0081 & 13.6731 & 44.4373 & 3.0081 & 13.6731 & 44.4373 \\
\hline 3 & 2.6052 & 11.8416 & 56.2789 & 2.6052 & 11.8416 & 56.2789 \\
\hline 4 & 1.7155 & 7.7977 & 64.0766 & 1.7155 & 7.7977 & 64.0766 \\
\hline 5 & 1.3942 & 6.3374 & 70.4139 & 1.3942 & 6.3374 & 70.4139 \\
\hline 6 & 1.0573 & 4.8060 & 75.2199 & 1.0573 & 4.8060 & 75.2199 \\
\hline 7 & 0.8273 & 3.7603 & 78.9802 & & & \\
\hline 8 & 0.7918 & 3.5992 & 82.5794 & & & \\
\hline 9 & 0.6453 & 2.9333 & 85.5127 & & & \\
\hline 10 & 0.5896 & 2.6799 & 88.1926 & & & \\
\hline 11 & 0.4217 & 1.9170 & 90.1096 & & & \\
\hline 12 & 0.3769 & 1.7134 & 91.8230 & & $\cdot$ & \\
\hline 13 & 0.3653 & 1.6605 & 93.4835 & & & \\
\hline 14 & 0.3098 & 1.4082 & 94.8916 & & & \\
\hline 15 & 0.2729 & 1.2406 & 96.1322 & & & \\
\hline 16 & 0.2459 & 1.1176 & 97.2499 & & & \\
\hline 17 & 0.1940 & 0.8818 & 98.1317 & & & \\
\hline 18 & 0.1479 & 0.6721 & 98.8038 & & & \\
\hline 19 & 0.1112 & 0.5057 & 99.3095 & & & \\
\hline 20 & 0.0892 & 0.4055 & 99.7150 & & & \\
\hline 21 & 0.0612 & 0.2782 & 99.9932 & & & \\
\hline 22 & 0.0015 & 0.0068 & 100.0000 & & & \\
\hline
\end{tabular}




\begin{tabular}{rrrrrr} 
Factor1 & Factor2 & Factor3 & Factor4 & \multicolumn{1}{c}{ Factor5 } & \multicolumn{1}{l}{ Factor6 } \\
$\mathbf{0 . 8 9 7 4}$ & 0.0895 & 0.0595 & 0.1027 & 0.0063 & -0.0338 \\
$\mathbf{0 . 8 7 3 6}$ & 0.1098 & 0.0392 & 0.0994 & -0.0146 & -0.1318 \\
$\mathbf{0 . 8 2 7 8}$ & 0.1156 & 0.1786 & 0.1529 & 0.0499 & -0.1733 \\
$\mathbf{0 . 6 2 7 0}$ & 0.3170 & -0.2140 & 0.1518 & 0.1174 & 0.2996 \\
$\mathbf{0 . 6 2 3 5}$ & 0.4708 & 0.1127 & -0.0450 & 0.1926 & 0.2265 \\
0.0366 & $\mathbf{0 . 8 0 0 6}$ & -0.2715 & 0.0385 & 0.0882 & -0.0681 \\
0.3764 & $\mathbf{0 . 7 0 4 9}$ & -0.0560 & -0.0009 & 0.2602 & -0.0759 \\
0.0806 & $\mathbf{0 . 6 2 2 9}$ & 0.0983 & 0.2886 & 0.0623 & -0.0079 \\
0.3663 & $\mathbf{0 . 5 2 5 6}$ & 0.4897 & 0.0663 & -0.0774 & 0.3191 \\
0.4673 & $\mathbf{0 . 5 0 7 4}$ & 0.3695 & 0.0842 & -0.3437 & 0.0447 \\
0.0982 & -0.0674 & $\mathbf{0 . 8 9 1 7}$ & 0.2341 & 0.0235 & -0.0587 \\
0.0041 & -0.0585 & $\mathbf{0 . 8 9 1 3}$ & 0.2133 & 0.0306 & -0.0192 \\
0.0392 & -0.1013 & 0.1136 & $\mathbf{0 . 7 4 3 7}$ & 0.0609 & -0.0286 \\
0.1617 & 0.2458 & 0.1622 & $\mathbf{0 . 7 2 9 3}$ & 0.0235 & 0.0442 \\
0.1627 & 0.2480 & 0.0510 & $\mathbf{0 . 6 7 9 8}$ & 0.2113 & 0.3047 \\
-0.0465 & 0.0660 & 0.4875 & $\mathbf{0 . 6 0 5 6}$ & 0.3456 & -0.0620 \\
0.2719 & 0.1844 & 0.3222 & $\mathbf{0 . 5 5 7 4}$ & -0.3742 & -0.1549 \\
-0.1252 & -0.0427 & -0.0787 & 0.0793 & $\mathbf{0 . 9 4 8 8}$ & -0.1122 \\
0.2316 & 0.3570 & 0.1993 & 0.1445 & $\mathbf{0 . 7 8 5 1}$ & -0.0851 \\
0.3492 & 0.5134 & 0.0819 & 0.1501 & $\mathbf{0 . 6 7 3 5}$ & 0.0164 \\
-0.3828 & -0.1098 & 0.0620 & -0.0501 & -0.1671 & $\mathbf{0 . 7 8 3 9}$ \\
0.4579 & 0.0340 & -0.3031 & 0.3182 & -0.0796 & $\mathbf{0 . 6 0 2 8}$
\end{tabular}

\section{Extraction Method: Principal Component Analysis. \\ Rotation Method: Varimax with Kaiser Normalization. \\ Rotation converged in 9 iterations.}

\section{Conclusion}

For each mandible accurate measurements were taken for 22 variables namely, (1) Symphyseal height, (2) Coronoid height, (3) Minimum breadth of ramus, (4) Maximum breadth of ramus, (5) Height of ramus right, (6) Height of ramus - left, (7) Body height, (8) Body thickness, (9) Body length,(10) Bigonial dimeter, (11) Bicondylar diameter, (12) Bimental breadth, (13) Mandibular angle, (14) Length of lowe jaw, (15) Interincisor width, (16) Interprmolar width, (17) Intermolar width, (18) Arch length, (19) Anthropometric arch length, (20) Anthropometric arch width, (21) Bicornoid width and (22) Mandibular index.The measurements were compared to the values of known sex to distinguish the sex of mandible. Every parameter, independent of other parameters provides certain percentage of certainity about the sex of mandible of unknown sex. This percentage of certainity significantly shifts when considered in combination with other parameters. Therefore, based only on one or two variables the sex of mandible cannot be decided. When all the variables are considered together and treated statistically, six factors have been extracted which could explain 75.2 percent of total variation in the data from all variables.Six dominating characters that possibly explain the nature of the mandible are (1) height of the ramus-right, (2) body thickness, (3) anthropometric arch width, (4) inter incisor width, (5) mandibular index and (6) mandibular angle.The present study reveals that mandibles of unknown gender can be sexed to the extent of 75 percent accuracy by carefully studying all the 22 parameters listed above and by statistically treating the data.

\section{References}

[1] Berry, A.C Factors affecting the incidence of nonmeterical skeletal variants 1995, Journal of Anatomy, Vol.120, p,519-535

[2] Brothwell, D.R. Digging up bones,III Ed. 1981, British Mueum (Natural History),Oxford University Press, London. Pages 82,83,90 to 95,100 .

[3] Brues, 1958 Attribution of sex, p.27-31, Complete skeleton of subadult.

[4] Camps, F.C Gradwoh's Legal Medicine,1968 Chap.II,P.126.Fig.45, and P.130., Bristol: John Wright\& Sons Ltd

[5] Christopher-L.B.Lavelle American Journal of Physical Anthropology,1972 Vol.36,p.213-220.

[6] Christopher-L.B.Laavelle American Journal of Physical Anthropology,1977 Vol.41,p.63-70.

[7] Clever, Biometric study of human mandible, Biometrics, 1937-38, Vol.28,P.84-122.

[8] avies,D.V. Gray's Anatomy Descriptive and Applied,1967, p.340-346,34 ${ }^{\text {th }}$ Edition, London, Longman's Green\&Co

[9] Diwan,C.V., Fakhruddin,S. and Shroff,A.G. Medical Collage, Aurangabad. Sexing the Mandible by Multivariate Analysis.1987 Journal of An Anatomical Society of India Vol.36, No.1,April 1987,p.42.

[10] Frazer, J.E Vol.36, No.1,April 1987,p.42.

[11] Funibunda, K.and J.N.S.MathewS,Journal of Anatomy, 2000,Vol.196,p.23-29.

[12] Giles,E,Discriminant function sexing of the humanskeleton. In Steward, T.D.(Ed.) personal identification iin Mass Disasters, 1970,pp.99-109, Washington, National Museum of Nature History.

[13] Hanihara, K. Sex diagnosis of Japanese skulls and scapulae, by means of Discriminant function. J.Anthrop. Soc.Nippon.1959,67,191-197. 
[14] Heereshchandra and Malaviya,G. The sexing of Human Mandible. Journal of the Indian Academy of Forensic Sciences, 1972,Vol.II,No.2,0.7.

[15] Hrdlicka,A. Lower jaw. The gonial angle. The bigonial breadth. American journal of physical Anthropology. 1940,Vol.27,p.284.

[16] ubert, M.Blalock,Social Statistics, II Ed. Mcgraw Hill Koga Kusha Ltd.1972, Tokyo.

[17] Inderbir Singh, Text book of Anatomy with Colour Atlas. $2^{\text {nd }}$ Edition, Vol.i., p.141-144

[18] Iordanidis,P. Annual Medicolegal Volume,1961-62,41-42

[19] Krogman,W.M..1962 The Human Skeleton in Forensic Medicine. Charles, C.Thomas Publisher. Spring Field. IIIlionis, U.S.A.

[20] Little Wood R.A. Physical Anthropology of the Eastern Highlands New Guinea, Vol.II,1972.p.180-182.

[21] Lockhart,R.D.,Hamilton,G.F.and Fyfe.F.W. 1965,Anatomy of the Human Skeleton, p.52,Second Edition, London. Faber\&Faber Ltd

[22] Mallik, C. Text Book of Forensic Medicine and Toxicology,1969, p.25, Academic publishers, 1, panchananghosh lane, Calcutta.C

[23] Martin,E.S. A study of an Egyptian series of Mandibles with special reference to Mathematical methods of sexing.1936 Biometrica.28:119-178

[24] Modi,J.P. Medical jurisprudence and Toxicology, Tripathi Pvt. Ltd.,1977, Bombay, $18^{\text {th }}$ Edition,p.27.

[25] Morant,G. A Biometric study of Human Mandible. Biometrica.1936, Vol.28.p.84-112.

[26] Polson, C.J.,Gee,D.J. and Bernard Knight 1985,The essentials of Forensic Medcine, $4^{\text {th }}$ Edition..p.46,52,53.pergamon press,Oxford, New york.

[27] Praksh, M., and Abdi, S.H.M. Department of Anatomy K.G.S. Medical College, Lucknow. Sexual Dimorphism in some Mandibular measurements. Jr. of Anatomical Society of India. Vol.36, No.1, April 1987, p.45

[28] Rajagopal Reddy K Sex Determination of Human Mandible,1978 Dissertation submitted to the Osmania University

[29] Ruck Biometric Study of Human Mandible, Biometrics, 1932, Vol.28, P.84-122.

[30] Seshaiah, E. 1992Sex Determination of Mandible, Dissertation submitted to the University of Health Sciences, Vijayawada

[31] .Shultz, A.H American Journal of Physical Anthropology-1924, Vol.7, p.155

[32] Stewart. T.D Adult American Negro Skeleton Sexed by Inspection (94\%). Evaluation of Evidence from the Skeleton. In: Gradwohi, REH (ed), Legal medicine, Mosby, St. Louis, 1954, p.407-450

[33] Surendranath An Introduction to Forensic Anthropology, 1989, Gian Pulishing House, New Delhi. Chap. IV, Attribution of Sex, p.27-31.

[34] 34.Tedeshi Forensic Medicine, 1977,Vol.II, p.1119, 1123, 1157, W.B. Saunders Company, Philadelphia

[35] 35.Tuli, A, R. Chodary, S. Chowdary and S. Agarwal Journal of Anatomy, 2000, Vol.197, p.343-347

[36] 36. Whittaker, D.K., A colour Atlas of Forensic Dentistry,1989, p.47,48, Wolfe Medical Publications Ltd., 2-16, Torrington Place, London 